\title{
[ARTIGO RETRATADO]
}

\section{MANEJO DO SOLO, INOCULAÇÃO DE SEMENTES E APLICAÇÃO DE NITROGÊNIO EM COBERTURA NO FEIJOEIRO DE INVERNO}

\section{MANAGEMENT OF SOIL, SEED INOCULATION AND APPLICATION OF NITROGEN ON THE COVERAGE OF WINTER BEAN}

Flávia Catiuci Robim da Silva', Orivaldo Arf ${ }^{2}$, Matheus Elache Rosa ${ }^{3}$, Carla Regina Pinotti ${ }^{4}$, Cleiton Herrera Rover ${ }^{5}$, Amanda Ribeiro Peres ${ }^{6}$

'Engenheira Agrônoma - Faculdade de Engenharia da UNESP - Campus de llha Solteira. ${ }^{2}$ Prof. Dr. Departamento de Fitotecnia, Tecnologia de Alimentos e Sócio Economia - Faculdade de Engenharia da UNESP - Campus de llha Solteira. ${ }^{3}$ Pós-graduando em Agronomia - Faculdade de Engenharia da UNESP - Campus de Illha Solteira. ${ }^{4}$ Cursando Agronomia - Faculdade de Engenharia da UNESP Campus de llha Solteira. ${ }^{5}$ Pós-graduando em Agronomia - Faculdade de Engenharia da UNESP Campus de llha Solteira. ${ }^{6}$ Pós-graduando em Agronomia - Faculdade de Engenharia da UNESP Campus de llha Solteira.

O Conselho Editorial da Revista Cultura Agronômica decidiu, após solicitação e análise, proceder à retirada formal do seguinte trabalho:

SILVA, F. C. R.; ARF, O.; ROSA, M. E.; PINOTTI, C. R.; ROVER, C. H.; PERES, A. R. Manejo do solo, inoculação de sementes e aplicação de nitrogênio em cobertura no feijoeiro de inverno. Cultura Agronômica, Ilha Solteira, v. 22, n. 1, p.81-94, 2013.

Uma vez que foram constatados que, parte dos dados deste artigo, foram publicados sem a concordância de todos os autores, na Revista Scientia Agrária, v. 12, n. 3, p.135-142, 2011, com o título: "Preparo do solo, inoculação de sementes e doses de nitrogênio em cobertura no feijoeiro comum de inverno irrigado". 
